\title{
GOVERNMENT EXPENDITURE ON SCIENTIFIC RESEARCH, 1962
}

$\mathrm{T}$ HE report of the Council for Scientific and Industrial Research for the year $1962 *$ records gross expenditure in the year ended March 31,1962 , of $£ 16,691,172$, compared with $£ 14,467,278$ in the previous year, and reduced to $£ 14,378,202$ by various receipts from industry and other sources for services rendered, of which $£ 1,120,677$ was from other Government departments and $£ 858,170$ from industry, $£ 214,143$ being received by the National Physical Laboratory. The net increase on 1961 was $£ 1,619,022$, and of this, $£ 258,922$ is on account of the National Lending Library for Science and Technology, which figures for the first time as a separate item (gross expenditure, $£ 304,249$ ) in the summary of expenditure. The staff again increased, from 6,224 to 6,525. Grants for special researches rose to $£ 2,275,060$, compared with $£ 1,495,469$ in 1961 , and contributions to the European Organization for Nuclear Research remained about $\mathfrak{1} 1,359,000$, while receipts reduced the contribution of $£ 198,800$ to NATO and the Organization for European Co-operation and Development scientific schemes to $£ 63,722$.

Postgraduate training awards amounted to $£ 1,289,903$ ( $£ 1,105,415$ in 1961) and the 1,604 new studentships, an increase of 9 per cent, brought the number current to 3,478 . Research fellowships increased from 54 in 1961 to 92 in 1962, and there are now 133 current. Of 51 awards for study abroad taken up, 23 were studentships and 28 fellowships, while 8 studentships and 16 fellowships were awarded to assist young British scientists returning from North America; 35 candidates with the diploma in technology obtained awards, compared with 11 in 1961. Of the 3,019 current research studentships, 413 were in biology and biochemistry, 205 in chemical engineering and metallurgy, 899 in chemistry, 128 in electrical and 203 in other fields of engineering, 214 in geology, 57 in the human sciences, 260 in mathematics, and 640 in physics. The advanced course studentships were distributed mainly in mathematics (88), physics (75) and engineering (other than electrical) (70), with 39 in chemical engineering and metallurgy, 29 in human sciences, 28 in biology and biochemistry, 22 in geology, 20 in electrical engineering and 15 in chemistry. All the 73 first-year studentships were again in chemistry, and of the 115 research fellowships, 56 were in chemistry, 29 in physics and 25 in biology and biochemistry, with 10 in geology.

Grants for special researches totalled 724, of which 321 were new, amounting to $£ 9,881,252$ in the year ended March 31, 1962; of these, 59 in nuclear physics totalled

* Department of Scientific and Industrial Research. Report of the Researeh Council for the Year 1962 . Pp. 62 . (Cmnd. 2027.) ((T)
H.M.S.O., 1963.) 4s. net. (See also p. 207 of this issue of Nature.)
$£ 3,870,624$, I7 in astronomy, $£ 1,045,796,121$ in technology, $£ 1,024,768$, and 165 in chemistry, $£ 957,551$. The 79 grants in low-temperature and solid-state physics totalled $£ 688,267,100$ grants in biology totalled $£ 535,417$, 33 in space research, $£ 520,926,58$ in geology and geophysics, $£ 469,689,50$ in the human sciences, $£ 419,601$, and 36 in physics, $£ 328,162$. During the academic year 1961-62, the Research Grants Committee considered 500 applications for grants with a total value of $£ 4,204,000$, compared with 447 applications valued at $£ 3,156,000$ in the previous year, and made 390 grants with a total value of $£ 2,313,000$, compared with 362 amounting to $£ 1,961,000$ in 1960-61. In addition, five grants were awarded for new major capital projects: $£ 534,200$ to the University of Cambridge for construction of a radio-telescope for research under Prof. M. Ryle; $£ 301,000$ to the University of Manchester for construction of a 125 -ft. steerable radiotelescope for research under Sir Bernard Lovell; and three grants totalling $£ 1,188,000$ for nuclear reactors for the University of London as a whole, the Universities of Manchester and Liverpool jointly and the Scottish and Northern Ireland universities. The Human Sciences Committee considered 36 applications with a total value of $£ 232,000$ and made 27 awards to the value of £ 132,000 .

With the exception of building research, which decreased slightly from $£ 785,413$ gross in $1960-61$ to $£ 781,037$ gross in 1961-62, and the Geological Survey and Museum, which decreased from $£ 586,640$ to $£ 578,969$ gross, the increased expenditure was distributed fairly generally over all branches of the Department's work. However, an unexplained jump in receipts by the Tropical Products Institute from $£ 22,300$ to $£ 399,472$ converted the increased total expenditure on the Institute of $£ 229,751$ into a credit of $£ 169,721$, an anomaly that seems to call for comment. The major increases are in the expenditure of the National Physical Laboratory (£2,033,109 gross; $\mathfrak{L 1}, 787,542$ in $1960-61$ ), the National Engineering Laboratory (£924,978; £811,164); the National Chemical Laboratory (£409,887; £384,073); road research $(£ 970,403$; $£ 872,805) ; \quad$ radio research (£320,413; £239,957). For fire research the corresponding figures are $£ 164,438$ and $£ 156,130$; for forest products research, $£ 194,619$ and $£ 185,985$; hydraulics research, $£ 232,661$ and $£ 203,931$; the Torry Research Station, $£ 226,696$ and $£ 215,192$; the Warren Spring Laboratory, $£ 471,181$ and $£ 453,985$; water-pollution research, $£ 183,550$ and $£ 165,336$; and for the Government Chemist's Laboratory, $£ 491,215$ and $£ 460,257$. Expenditure on headquarters administration decreased from $£ 758,126$ in $1960-61$ to $£ 615,536$, or slightly below the 1959-60 figure.

\section{EDUCATION IN MATERIALS SCIENCE}

$\mathrm{T}$ HE first conference on "Education in Materials Science" and technology in the United Kingdom was held in Banbury during May 18-19 under the general chairmanship of Mr. L. Holliday (Shell Chemical Co., Ltd.). The conference was arranged by the Steering Committee of the Working Party on Materials Science and Technology, set up by the Institution of Chemical Engineers. Some thirty representatives from universities, colleges of advanced technology and industry were invited.
The first session dealt with the situation in materials science in the United States and in Britain and went on to consider possible starting points for materials science courses and research in universities. Sir Harry Melville, secretary of the Department of Scientific and Industrial Research, introduced the subject of the conference and emphasized its importance not only in universities and colleges but also in industry and Government scientific establishments. It was of immediate concern to the Department of Scientific and Industrial Research, which 
had to keop now developments in constant review so that finance could be found for worth-while proposals.

Although it was not known what the outcome of the Robbins Committeo would be, Sir Harry thought that it was likely that Britain would continue with the three-year undergraduate courses, and because these were now so crowded it would be difficult to introduce in dopth the concepts of materials seience without risking superficiality in the courses. He thought that this problem would be least serious in metallurgy departments because they have done this kind of work in universities over the years. The limitations of existing courses could be met by the establishment of postgraduate courses, support for which was now provided by his department. Sir Harry considered that one of the sorious problems of creating an interdisciplinary subject was to achieve something greater than the arithmetical sum of the parts. This was a problem of achieving real co-operation and co-ordination so as to influence the mental attitudes of the students. He was anxious that Britain should try to meet the developing situation by action now, so as not to be forced to act later under pressure from influences outside the country.

Prof. R. L. Sproull, head of the Materials Science Centre, Cornell University, and chairman of the Advanced Research Projects Agency activity there, reviewed the situation in the United. States. He recalled that some six years ago many currents of opinion seemed to be running in the same direction pointing to the absence of adequate materials for the many now technological projects, in particular atomic energy and astronautics. The problems came to a focus within the Atomic Energy Commission and there was a proposal to form a National Laboratory for Materials. It was soon realized that there were not enough men with the right background and attitudes to staff such a laboratory and urgent decisions were taken to provide training to produce this type of man for the future.

It was noticed that in some of the big industrial laboratories in the United States it was possible to bring sophistication from various scientific fields to bear on problems and frequently the outcome from this approach was strikingly successful. It was also noticed that students are more readily attracted to those subjects that contain the word 'science' in their titles. Even so, a very high proportion of graduates who were working on problems of materials had in fact been trained in high-energy physics. This was recognized as wasteful, and it was decided to establish a series of interdisciplinary laboratories in several university institutions devoted to materials science. There are now twelve such interdisciplinary laboratories supported by the Advanced Research Projects Agency, with two more supported by the National Aeronautics and Space Agency and an additional one supported by the Atomic Energy Commission.

University departments had not, in general, been equipped with sophisticated apparatus of the type students would eventually use for ressarch and development in Government and industrial laboratories. Therefore, ono objective was that university departments should be equipped to about the same standard as some of the best industrial laboratories. In response to Government support, the chosen university institutions agreed to produce more Ph.D.s, to undertako research which would be broadly in keoping with the trends in materials development and to use an interdisciplinary approach to research. They were in fact trying to produce a new breed of man and not merely to achieve a simple addition of disciplines. Prof. Sproull was in favour of the development of materials science courses without reference to existing disciplines although this had not, in general, been possible in the United States.

Prof. E. W. J. Mitchell (University of Reading) described how he had tackled the problem of achieving depth while covering the essential fundamentals required in materials research work. This could be achieved by a fairly ruthless pruning of the conventional physics course, leaving out treatment in depth of such topics as high-energy physics, electronics and optics, and streamlining the teaching in some other subjects. The objective was to try to impart to the students an understanding of some of the structuresensitive phenomena and an appreciation that they could be studied in an intellectually stimulating fashion. Prof. Mitchell's undergraduate course forms one of thres options within the school of physical sciences at the University of Reading.

Prof. D. A. Wright explained that because there was much activity in high-energy physics at Durham it had been appropriate to introduce applied physics and to concentrate on electrical materials in toaching and research. The University hopes eventually to introduce postgraduate courses in this field.

Profs. A. G. Quarrell and V. N. Douglas emphasizgd strongly the intərdisciplinary nature of all technology. They pointed out the distinctions between solid-state physics and activities such as physical metallurgy and glass technology, which could not avoid the complexities of real industrial problems. Prof. Quarrell warnod against thinking that the study of materials science was specifically a new feature. At Sheffield this had been tho case for some time where the Faculty of Metallurgy included glass technology and refractories as well as metallurgy. He thought that technological subjects should stand in their own right as university disciplines and that they could not be adequately imparted in short postgraduate courses given to people who had not previously had some understanding of the complex situations involved.

Prof. R. W. Cahn (University College of North Wales, Bangor) presided at the second sossion whon the discussion embraced "the relationship between materia!s science and other disciplines, the problem of financing materials science teaching and research, and the problem of university recruitment".

Prof. T. K. Ross (Manchester College of Science and Technology), speaking for chemical engineering, said that the relationship between materials science and chemical engineering might at first sight appear slight but was by no means unimportant. The chemical engineer tended to think in terms of constructional materials for process plants and the problem of environment usually represented corrosion. In his opinion, the postgraduate field had most to offer.

Mr. A. Kennaway (B.T.R. Industries, Ltd.) contended that mechanical engineers required to be better educated in materials science. They should know more about the plastic range in metals, the criteria for failure and the technical proporties in general in relation to structure. The properties of other materials such as plastics were often investigated by chemists and physicists with the result that the available information was not in a form that the engineer could use. Mr. Kennaway could see no case for the unification of the technologies, as compared with the science of materials.

Prof. A. J. Wildschut (Technical University, Delft), said it was surprising, on reflexion, how little was known about materials. The civil engineer was interested in a wide range of materials - the 'big volume materials' such as clay, soil and stone, which must be cheap, and the 'small volume materials' such as brick, metal and wood. He quoted a number of novel applications and emphasized the importance of durability in structural materials which were difficult to use up to their physical limit. Dimensional stability was important in metals, for example, and stiffness in structure, while a weakness in an expensive joint could impair the success of a major civil engineering project. Improved knowledge of all materials of construction was important to the civil engineer

Prof. E. H. Rhoderick (Manchester College of Science and Technology) described the courses in materials 
science designed for electrical engineers with a bias towards electronics interests, which included subtle and complicated techniques and involved, for example, superconductors and cryogenic techniques. The courses presumed that the materials scientist was not essential for inventions but he was required for the development of inventions. Third-year electrical engineering students at Manchester were given an extensive course in properties of materials, including new materials. A further course was available at postgraduate level. The stimulus came from linking the materials work to electrical engineering.

In the discussion that followed, it was pointed out that a postgraduate course has been designed at the Imperial College of Science and Technology. This represented a co-operative effort between seven disciplines because the interdisciplinary approach was considered to be essential. Another speaker contended that materials science could make its greatest contribution through the development of a common language. We were not disseminating adequately the existing knowledge of materials, and practice in industry tended to lag too much behind research - the growth in knowledge in the field had outstripped the applications. A representative of the Department of Scientific and Industrial Research spoke on the problem of financing materials science teaching and research. Special emphasis was being given by the Department to the needs of materials science, and the long-term financial implications were under investigation. This led to a lively and prolonged discussion on the question of the adequacy of the financial provision, particularly for postgraduate students and courses. Prof. G. Ball (Imperial College of Science and Technology) introduced the subject "the problem of university recruitment" and emphasized what had been said earlier - the tendency of the schoolboy to think in terms of pure science. For this reason alone it might be worth while to retain the word 'science' in the title of courses, with the view of attracting better than average students. In the long term, the social attitude to 'technology' might change. The attitude to materials science as a discipline could be influenced by the provision of suitable text-books for schools. One speaker claimed that pure science was more attractive to the schoolboy by reasons of the so-called 'convertibility' with which it endowed its students, but that it was a mistake, however, to fill higher posts with those trained in narrow specialisms such as rubber or refrigeration technology.

At the third session the chair was taken by Prof. Sproull. Dr. P. E. Evans (Faculty of Technology, University of Manchester), opening a discussion on materials science and the established disciplines, stressed the need for a fresh and unfettered approach to the subject and the importance of engendering thinking in terms of materials from the beginning of the course. A good case could be made out for teaching materials science as a first degree subject. He thought that there might be a danger that the established departments of applied science would regard materials science departments as competitors for limited funds, and, under Britain's present educational system, a limited number of students. The trained materials scientist required is one who not only has specialized knowledge in one field of materials but also has a thorough understanding of materials generally.

Dr. N. F. Astbury (director of Research, British Ceramic Research Association) considered the possible role of a Materials Science Council: whether it could be a viable unit and how it could best operate. He suggested that all rational research is good but only some is timely, and that we are not getting the maximum co-ordination of national effort since much materials rescarch in the United Kingdom is done in a vacuum, thus becoming sterile because it is not stimulated by the materials user. $\mathrm{He}$ pointed out that there is no civil agency for coordinating materials research in Britain. The relation of a Materials Science Council to existing bodies would be a matter for careful thought, since materials science cuts across several entrenched interests. Opinion would seem to favour a council formed from the relevant existing professional and scientific bodies.

Dr. H. M. Finniston (International Research and Development Co., Ltd.), talking on materials research institutions, suggested that the United Kingdom cannot afford the pursuit of knowledge for its own sake so that 'research' must not always be interpreted as 'pure research'. Any materials research institute would have to be Government supported, interdisciplinary and related to some other continuing function, for example, teaching or industry; it could only be founded at the expense of existing institutions. In general, he was opposed to the foundation of a single national institute. He added that Britain cannot and should not copy the American approach. Mr. Zvegintsov (National Research and Development Corporation), discussing the types of materials scientist needed by industry, said that the paradox in science and technology in this field was the requirement for greater specialization with greater hybridization. He stressed that the essential background knowledge required was the relation of properties to structure and that the need for the imaginative creative step was increasing.

In the discussion that followed, it was suggested that a Materials Science Council could collate and disseminate information on existing and proposed materials science courses in addition to promoting conferences on themes cutting across several disciplines. It was said that Britain cannot afford a proliferation of research institutions.

In conclusion, it was agreed that the following items summarized the tenor of the conference:

(1) There is a real need for an expansion of existing postgraduate courses in materials science.

(2) There should be a limit to the number of institutions offering courses in materials science because such an institution must be of a minimum size before it can be effective.

(3) The best kind of materials science course is organized by cutting across the boundaries of departments of both pure and applied science.

(4) The lack of Department of Scientific and Industrial Research advanced studentships is a grave handicap to the development of materials science courses.

(5) There appears to be no case to support any plan for setting up special research institutions to be devoted to materials science.

(6) Experience in materials science courses so far shows that it will be necessary to interest the schoolmaster and the schoolboy in this subject. There are various ways in which this can be done, but one which calls for attention is the re-writing of parts of school physics text-books.

(7) It has been stated that the reason why schoolmasters recommend that their best students read pure science is because physics and chemistry are more 'convertible' than a subject like materials science or a technological subject. This is questioned. Experience from such universities as Sheffield shows that graduates in technological subjects are at least as adaptable as graduates in pure science.

(8) Sir Harry Melville, secretary of the Department of Scientific and Industrial Research, would welcome the opportunity to meet representatives of the univorsities and colleges of advanced technology concerned with materials science and technology, to discuss the forward planning of teaching and research.

It was resolved to hold a further conference on the same theme in 1964. Prof. Mitchell, of the University of Reading, has agreed to co-ordinate the arrangements for this.

L. Holliday

J. G. BALI

P. E. Evans

J. B. BrenNan 